\title{
Notas para un debate sobre el significado de la ganadería en la historia de la región Caribe colombiana
}

\author{
Sergio Paolo Solano $D .^{(*)}$
}

Recibido: marzo de 2011

Aprobado: mayo 2011.

\section{Resumen:}

En este artículo paso revista a las diversas interpretaciones sobre el significado histórico de la ganadería en la región Caribe colombiana, en especial al proceso intelectual y político que llevó a formar un cuerpo de opiniones llamado por Luís E. Nieto Arteta "antilatifundismo sociológico", como también a los desafíos planteados a esta tradición por las investigaciones de Eduardo Posada. En el marco de esa discusión propongo mis puntos de vistas en torno a las relaciones y los conflictos escenificados entre la expansión ganadera y ciertas formas de propiedad corporativa de la tierra, como eran los terrenos de los resguardos de los indígenas y los ejidos o tierras comunales de las poblaciones.

\section{Palabras claves:}

Historiografía, Caribe colombiano, hacienda ganadera, tierras indígenas resguardadas.

\section{Abstract:}

This article reviewed the different interpretations about the historical significance of livestock in the Colombian Caribbean region, especially the intellectual and political process that led to the formation of a body of opinion called by Luis E. Nieto Arteta "antilatifundismo sociological", as well as the challenges posed by this research tradition Eduardo Posada. As part of that discussion, I propose my views on the relations and conflicts between the staged expansion of cattle raising and some forms of corporate ownership of land, as were the guards of the land of indigenous and communal lands of ejidos of populations.

\section{Key words:}

Historiography, Colombian Caribbean, cattle ranch, sheltered indigenous lands.

\footnotetext{
${ }^{(*)}$ Profesor Asociado del Programa de Historia, Facultad de Ciencias Humanas, Universidad de Cartagena de Indias, Colombia. Miembro del grupo de investigaciones Frontera, Sociedad y Cultura. Recientemente publicó artículos en las revistas H-Industri@ No 4 (Buenos Aires, Universidad de Buenos Aires, 2009); Amauta $\mathrm{N}^{\circ} 13$ (Barranquilla, Universidad del Atlántico, 2009); Memorias $\mathrm{N}^{\circ} 10$ (Barranquilla, Universidad del Norte, 2009); Revista de Estudios Sociales № 31 (Bogotá, Universidad de los Andes, 2008); Historia Caribe No 13, Barranquilla, Universidad del Atlántico, 2008; Cuadernos de Literatura de Hispanoamérica y el Caribe $\mathrm{N}^{\mathrm{o}}$ 7, Barranquilla, Universidad del Atlántico-Universidad de Cartagena, 2008; Palobra $\mathrm{N}^{\circ}$ 9, Cartagena, Universidad de Cartagena, 2008; Historia Crítica $\mathrm{N}^{\circ}$ 34, Bogotá, Universidad de los Andes, 2007; Justicia No 12, Barranquilla, Universidad Simón Bolívar, 2007. ssolanod@unicartagena.edu.co
} 


\section{Presentación}

$\mathrm{D}$ esde hace varios decenios las consecuencias económicas, sociales, culturales y políticas de la ganadería ha suscitado puntos de vistas encontrados en Colombia y en su región Caribe. Tanto quienes la condenan como causa del atraso del país, como quienes la defienden por ser la única posibilidad en medio de unas condiciones ambientales, técnicas y de capitales adversas para otras actividades agrícolas, reconocen que la ganadería ha marcado la vida de muchas generaciones de las gentes campo colombiano y que a su alrededor se ha construido buena parte del mundo social, político, cultural y folclórico de sus regiones, en especial de la Costa Caribe ${ }^{1}$.

Durante la segunda mitad del siglo XX los estudios sobre el mundo agrario colombiano estuvieron marcados por dos grandes influencias. Por un lado las investigaciones realizadas desde diversas vertientes del marxismo y con puntos de vistas diferentes sobre la evolución histórica de la propiedad territorial, las características de las relaciones sociales entre el campesinado y los poseedores de grandes propiedades territoriales, las peculiaridades del poder político en las zonas agrarias, la naturaleza social del campesinado y su posible función en un proceso de cambio social. Muchos de estos estudios llevaron las patentes de fuertes sesgos ideológicos, políticos y teóricos como lo había manifestado por los años de 1970 Magnus Mörner, y formaron parte de los debates sobre unas interpretaciones del pasado que debían estar al servicio del cambio social ${ }^{2}$.

Esas discusiones fueron alimentadas por -y esta es la segunda influencia- una tradición intelectual que se fue ensamblando en Latinoamérica desde finales del siglo XVIII con algunos ilustrados del periodo borbónico ${ }^{3}$, y luego sistematizada por los intelectuales y políticos de corte liberal que ascendieron al poder durante el tercer cuarto de la siguiente

\footnotetext{
${ }^{1}$ Magnus Mörner, "La hacienda hispanoamericana: examen de las investigaciones y debates recientes”, en Enrique Florescano (coord.), Haciendas, latifundios y plantaciones en América Latina, México, Siglo XXI, 1975, pp. 15-48. Algunas ideas sobre los debates sobre la ganadería argentina en: Juan C. Garavaglia y Jorge Gelman, "Mucha tierra y poca gente: un nuevo balance historiográfico de la historia rural platense (1750-1850)", en Historia Agraria N ${ }^{0}$ 15, Murcia, Universidad de Murcia, 1998, pp. 29-50; Noemí Girbal-Blacha, "La historiografía agraria argentina: enfoques microhistóricos regionales para la macrohistoria rural del siglo XX (1980-1999)", en Estudios Interdisciplinarios de América Latina y el Caribe vol. 12, No 2, Tel Aviv, Universidad de Tel Aviv, 2001. http://www.tau.ac.il/eial/XII_2/girbal.html (Consulta: diciembre 13 de 2005); Andrea Reguera, "Gran propiedad, empresarios e instituciones económicas en la región pampeana (1850-1930)", en Signos Históricos N ${ }^{\circ} 15$, México, Universidad Autónoma Metropolitana-Iztapalapa, 2006, pp. 44-69. http://148.206.53.230/revistasuam/ signoshistoricos/incluye/getdoc.php?id =340\&article= 190\&mode=pdf (Consulta: enero 14 de 2007).

${ }^{2}$ M. Mörner, "La hacienda hispanoamericana: examen de las investigaciones y debates recientes", p. 41; Alexander Betancourt, Historia y nación, Medellín, La Carreta, 2007, pp. 196-199.

${ }^{3}$ Hans-Joachim König, En el camino hacia la nación, Bogotá, Banco de la República, 1994, pp. 101 y ss.; Renán Silva, "El descubrimiento de la economía política en la Nueva Granada a finales del siglo XVIII", en Anuario Colombiano de Historia Social y de la Cultura No 29, Bogotá, Universidad Nacional, 2002, pp. 109-133.
} 
centuria, tradición que achacaba la causa del atraso económico y social de esta parte del mundo a la concentración de la propiedad territorial en pocas personas.

En la páginas que siguen paso revista a las diversas interpretaciones sobre la significación histórica de la ganadería en la región Caribe colombiana, en especial al proceso intelectual y político que llevó a formar un cuerpo de opiniones llamado por Luís E. Nieto Arteta "antilatifundismo sociológico", como también a los desafíos planteados a esta tradición por las investigaciones de Eduardo Posada. En el marco de esa discusión propongo mis puntos de vistas en torno a las relaciones y los conflictos escenificados entre la expansión ganadera y ciertas formas de propiedad corporativa de la tierra, como eran los terrenos de los resguardos de los indígenas y los ejidos o tierras comunales de las poblaciones.

\section{El ensamble de una tradición antilatifundista. Liberales y el campo en el siglo XIX}

La influencia que tuvo el pensamiento liberal decimonónico entre los intelectuales y políticos del siglo XX la sugirió en 1942 Luís Eduardo Nieto Arteta al observar que sus propios puntos de vista eran tributarios de las elucubraciones de aquellos, a las que llamó "antilatifundismo sociológico". Con este concepto designó al conjunto de ideas sobre la propiedad agraria, los usos del suelo, las relaciones sociales y la economía de libre empresa, vistas como el resultado de una evolución histórica y solo posible en las sociedades que desarrollaron la agricultura y que vivían concentradas, lo que a su parecer representaba un avance con relación a una lectura de la propiedad territorial solo en términos jurídicos y como una condición natural de todas las sociedades ${ }^{4}$.

Las llamadas reformas liberales de mediados del siglo XIX estimularon la construcción de esas reflexiones por parte de la generación de los intelectuales liberales nacida después de la derrota del colonialismo, la que edificó algunas interpretaciones económicas y sociológicas sobre el pasado colonial ensambladas a punta de imágenes contrarias a los aspectos de las reformas liberales que se querían exaltar como transformaciones significativas. El desafío que afrontaron los liberales de ese entonces al intentar aclimatar en Colombia una economía agroexportadora los llevó a reflexionar sobre la economía agraria y a criticar las formas de propiedad existentes en la república que prolongaban la economía colonial, como también a los obstáculos para el progreso económico representados en los bienes amortizados, los censos, mayorazgos y capellanía, las formas corporativas de posesión y usufructo del suelo como los resguardos indígenas, ejidos de los municipios y tierras de mancomunidad 5 .

${ }^{4}$ Luís E. Nieto Arteta, Economía y cultura en la historia de Colombia, Bogotá, Oveja Negra, 1973, pp. $125-135$

${ }^{5}$ Salvador Camacho, Escritos varios, Bogotá, Librería Colombiana, 1892, pp. 147-148, 601, 675-694; Notas de viaje, tomo I, Bogotá, Banco de la República, 1973, pp. 41-42, 75-76, 109, 123-126; José María Samper, Ensayo sobre las revoluciones políticas y la condición social de las Repúblicas Colombianas, Bogotá, Biblioteca Popular de la Cultura Colombiana, 1945, pp. 45-62; Miguel Samper, Escritos políticoeconómicos tomo III, Bogotá, Banco de la República, 1977, p. 276. Las críticas al régimen agrario colonial y a su supervivencia bajo la república reproducían en sus líneas gruesas el ideario de los ilustrados europeos del dieciocho que relacionaba la sociedad feudal con unas relaciones sociales de 
Fue con Aníbal Galindo (1883) que apareció bien marcada la disyuntiva entre el desarrollo basado en la gran o en la pequeña y mediana propiedad territorial. Ávido lector, liberal radical, ministro de hacienda y conocedor del ramo de las estadísticas nacionales dado que trabajó en ese campo para varios gobiernos liberales, aspiraba a un país de pequeños y medianos propietarios y en consecuencia se preocupó por la imprevisión estatal en la concesión de baldíos a particulares, pues no tenía en cuenta, “... los derechos naturales del hombre a la accesión del desierto [baldíos], ni a las necesidades ni a la independencia política y personal de las generaciones presentes y futuras". Por eso condenó drásticamente el latifundio por creerlo la causa del atraso del campo, y para demostrar la justeza de su reprobación insistió en la necesidad de estudiar las condiciones en que se desenvolvía la pequeña propiedad (número de campesinos propietarios, extensión de las parcelas, cultivos, técnicas aplicadas, rendimiento, condiciones de competencia con la hacienda, estado de bienestar o miseria de los campesinos), las condiciones en que se hallaban los arrendatarios tanto en relación con la hacienda como con la pequeña y mediana propiedad (formas de arrendamiento y de pago de la renta, estabilidad de los contratos, estado de bienestar del arrendatario, funcionamiento de las leyes para contener las arbitrariedades de los propietarios), condiciones de vida de los jornaleros (formas de salarios, cultivos en que se aplica el trabajo asalariado y su rentabilidad). Galindo consideraba que el único factor que crea riqueza social es el trabajo, y que el latifundio como forma de monopolio sobre el suelo permitía al propietario apropiarse de parte de la riqueza que crea el trabajo social, mientras que oprime a los trabajadores, dado que la consecuencia de no tener independencia económica era "caer en la miseria o en la servidumbre".

Desde su punto de vista la vida agraria colombiana del siglo XIX estaba determinada por la existencia de grandes zonas de fronteras abiertas, y el latifundio era el resultado de la apropiación de extensos territorios baldíos, ocasionando conflictos sociales por la propiedad y posesión del suelo. Conocedor de la obra de David Ricardo, quien había insistido en criticar la gran propiedad agraria inglesa y de la renta diferencial que le producía a los grandes terratenientes que se apropiaban de una buena porción de las ganancias de la burguesía agraria e industrial limitando el desarrollo económico, Galindo inauguró una reflexión de corte liberal y sociológica que liga la propiedad territorial con ciertas formas sociales y políticas de subordinación o dependencia, como también lo había hecho en 1861 José María Samper quien ataba la posesión comunitarias de tierra (resguardos) a formas serviles que impedían la individualización, y en consecuencia exigía liberar las tierras corporativas, para así evitar continuar atando a la población productiva a

servidumbre que negaba el desarrollo de la individualidad y concedía privilegios, la concentración de la propiedad territorial como el resultado de las expansiones conquistadoras de algunos pueblos y las cargas fiscales que entrababan la libre iniciativa económica. En el Caribe colombiano ese ideario se conocía gracias a filósofos y a los historiadores franceses del periodo de la restauración. Ver los inventarios detallados de las obras de economía, historia, filosofía y derecho constitucional que reposaban en la biblioteca de la Universidad de Cartagena en "Biblioteca en venta" y "Libros", en Biblioteca Luís Ángel Arango (Colombia) [BLAA], Colección de prensa microfilmada, Semanario de la Provincia de Cartagena, Cartagena, agosto 14 de 1842, y agosto 16 de 1846; "Inventario del Colegio del Estado. Biblioteca", en Gaceta de Bolivar, Cartagena, septiembre 24, octubre 9, 10, 17, 19 de 1874; "Inventario de libros, mapas, aparatos y demás útiles de enseñanza que existen en el Colegio del Estado...”, en Diario de Bolivar, Cartagena, julio 17 de 1878. 
la agricultura, y dificultando el surgimiento de una compleja división del trabajo desprendida de la agricultura ${ }^{6}$.

Las condiciones de la vida rural en el siglo XX sirvieron para que muchas de esas críticas se prolongaran. Por un lado se acentuó el proceso de concentración de la propiedad territorial; por otra parte el crecimiento de la población presionó por una mayor producción de alimentos, al tiempo que el incipiente desarrollo industrial exigía materias primas de origen agrario. Fue durante el decenio de 1920 que se pensó en la situación del campo (tenencia de la tierra, tecnología agrícola, relaciones sociales y laborales, formas de remuneración del trabajo y la economía de mercado, encadenamientos entre el sector agrario y el industrial urbano) como un problema nacional, en la medida en que el naciente proceso de industrialización y de consolidación del mercado interno demandó infructuosamente que la producción agrícola respondiera satisfactoriamente a la demanda de las industrias y de alimentos de la canasta familiar para la reproducción de la fuerza de trabajo. Esto porque la inelasticidad de la producción agrícola, el encarecimiento de los productos de primera necesidad, los problemas sociales por costo de vida y las exigencias de aumento de salarios, implicaban una reducción de los márgenes de ganancia de los industriales, en beneficio de los terratenientes ${ }^{7}$.

En medio de esta situación sectores políticos, industriales, trabajadores y de campesinos empezaron a señalar la existencia de un problema agrario nacional que debía ser resuelto. Ese problema fue percibido en dos ámbitos: la concentración de la propiedad territorial que sustraía enormes áreas del suelo de la agricultura de mercado, y unas relaciones de trabajo que ataban al campesino a la tierra impidiéndole su desplazamiento hacia las áreas de

\footnotetext{
${ }^{6}$ Aníbal Galindo, Estudios económicos y fiscales, Bogotá, Anif-Colcultura, 1978, pp. 189-206. Al parecer las críticas a la gran propiedad inoficiosa eran moneda corriente entre algunos sectores ilustrados de las distintas regiones pues en 1864, a propósitos de los problemas que afrontaron las autoridades de los distritos al intentar aplicar una ley sobre los ejidos municipales, Eloy Porto, gobernador de la provincia de Cartagena, en el Estado de Bolívar, se expresó de una manera tajante frente a las resistencias de los grandes propietarios que tenían tierras en las inmediaciones de las cabeceras municipales y que se oponían a que se aplicara aquella ley: "Pero sea que se adopte esta medida o cualquiera otra semejante, si encarezco a U. tome bajo su proteccion ésta medida que a la larga conducirá a declarar libre la tierra que los pueblos han recibido de Dios, como el aire i el mar. Yo soi de los que opinan que el hombre no debe poseer mas que la tierra que labra, mientras la tiene cultivada, i esto no se opone en manera alguna al derecho de propiedad que yo creo necesario para el adelanto de los pueblos; Señor: el que construye una casa, una cisterna, \&, \&, o establece plantaciones que exijan cuidado i sacrificios, es justo que posea aquello con esclusion de toda otra persona. Pero: ¿es racional que mientras un individuo se llama propietario de terrenos inmensos que ni conoce, ni saben lo que producen, otro hombre no tenga un palmo que regar con el sudor de su frente para mal alimentarse i sostener su penosa existencia? ¿i quién dio aquel ese derecho? Examinemos, i al fin se encontrará la espoliacion, el vandalismo, la conquista, siempre el derecho del mas fuerte. Los Gobiernos encargados de administrar justicia no deben tolerar mas tiempo este monopolio chocante e inocuo, como ya casi por unanimidad rechazan la esclavitud". Ver: BLAA, "Informe q' produce el Gobernador de la Provincia de Cartajena de conformidad con el inciso 29 artículo $7^{\circ}$ de la lei de 13 de febrero de 1860, sobre Réjimen Político", en Gaceta Oficial del Estado Soberano de Bolivar, Cartagena, 10 de abril de 1864.

${ }^{7}$ Jesús Bejarano, "Contribución al debate sobre el problema agrario", en Francisco Leal (comp.), El agro en el desarrollo histórico colombiano. Ensayos de economía política, Bogotá, Punta de LanzaUniversidad de los Andes, 1977, pp. 33-34.
} 
demanda laboral y lo sustraían de la economía monetaria, lo que contraía al mercado para los bienes industriales.

Fue en este contexto que Alejandro López en su ensayo Problemas colombianos (1927) volvió a presentar el tema de la gran propiedad territorial en Colombia y las limitaciones que imponía al crecimiento económico y al surgimiento de una sociedad moderna. Sus referencias para criticar la economía ganadera extensiva fue el contraste que hizo entre la colonización antioqueña de las faldas de las cordilleras central y occidental, y la de los valles de los ríos Cauca y Magdalena, desarrollándose en las faldas de las montañas la economía cafetera y en los valles los hatos ganaderos. Al área cafetera la caracterizó como una economía dinámica, más eficiente y productiva al estar basada en pequeñas y medianas propiedades que vincula gran cantidad de fuerza de trabajo, introduce mejoras técnicas dado su carácter de agricultura intensiva, y en consecuencia da origen a una economía de mercado significativa que a su vez favorece el crecimiento de las áreas industriales urbanas. Como contrapunto colocó a la economía de pastos de los mencionados valles colonizados por antioqueños, a la que no caracterizó como una industria agropecuaria sino como una economía de pastoreo colocada al nivel de la recolección de frutos que empleaba poca mano de obra por hectárea. A esta le achacó su carácter extensivo, el poco empleo de brazos que no guardan relación con la propiedad y por tanto carecen de independencia, la demanda de grandes inversiones. La lectura que hizo López de las consecuencias de la ganadería para las zonas en que se había desarrollado era pesimista:

... [el] cultivo extensivo tiene relación con la mayor parte de los problemas nacionales, estorbando... el desarrollo económico y suscitando nuevos problemas. Tiende a producir la "abundancia de brazos" en una regiones y de la migración de la población en otras; plantea problemas agrarios; impide la concentración de la población en el área ya conquistada, adaptada y con mercados disponibles, y dificulta por eso la creación de nuevas industrias, cuya viabilidad depende de una buena demanda; con ello se agravaba el problema fundamental de los transportes y se acentúa la carestía de los mantenimientos ${ }^{8}$.

Las ideas de Alejandro López sobre la tenencia de la tierra en el siglo XIX suponen que el crecimiento económico depende de un modelo agroexportador cuya suerte debe estar ligada a la descorporativización y libre comercialización de la propiedad territorial y a la creación de relaciones sociales y laborales libres en el campo. En sus propios términos, el latifundio "Contribuye poderosamente a obstaculizar el lento desarrollo económico de la América castellana, porque limita el poder de compra y las posibilidades de consumo de las grandes masas campesinas". Medidas que debieron favorecer el crecimiento económico

8 Alejandro López, Escritos escogidos, Bogotá, Colcultura, 1976, pp. 41-72; Eduardo Posada, "Regionalismo, café y nuevo liberalismo en la obra de Alejandro López", en El desafio de las ideas. Ensayos de historia intelectual y política colombiana, Medellín, Universidad Eafit-Banco de la República, 2003, pp. 1234-138. 
como las reformas liberales en materia agraria y social (desamortización de bienes de manos muertas, redención de censos, abolición de diezmos, supresión de la esclavitud), tuvieron como resultados el fortalecimiento del latifundio.

Entre 1930 y 1960 fue muy poco lo que se agregó a esta interpretación. Políticos y economistas, inspirados en el pensamiento liberal o marxista reafirmaron el cuerpo de ideas expuesto por Alejandro López, mientras que hacían de las obras de los liberales de mediados del siglo XIX el principal soporte de sus análisis ${ }^{9}$. En los años treinta y cuarenta, la Contraloría General de la República publicó la Geografía Económica de Colombia por departamentos, cuerpo de investigaciones llevado a cabo por comisiones de intelectuales nativos de cada uno de las regiones y personal especializado del área de estadística de esa entidad de control fiscal. En 1942 se publicó la Geografía económica de Colombia. Bolivar, obra importante porque por vez primera se presentaba una síntesis de la evolución de la propiedad territorial en la región costeña, que en buena parte seguía el modelo de Alejandro López ${ }^{10}$. Algunos círculos de intelectuales y políticos de las distintas regiones del país retomaron estas ideas en concordancia con los problemas que se fueron presentando, en especial con los relacionados con las luchas de los campesinos por acceder o defender las tierras y con los impasses por los que atravesaba el desarrollo industrial.

En el caso de la región Caribe este último aspecto se evidenció con el desarrollo de la industria textil, la que en sus primeros años procesó materias primas (hilaza) importada. Pero cuando el gobierno de Carlos E. Restrepo (1912-1916) gravó de forma onerosa la importación de esa materia prima para favorecer a las textileras de Antioquia, aquéllas se vieron obligadas a montar secciones de hilado y a intentar abastecerse de insumos nativos. De ahí vinieron los tímidos impulsos a la producción algodonera regional en la margen oriental del río Magdalena, en buena parte del departamento del Atlántico y en el norte del departamento de Bolívar. Prontamente la producción nativa mostró sus limitaciones, lo que llevó a que por los años treinta y cuarenta la relación entre el desarrollo industrial y la producción agraria se convirtiera en motivo de cavilaciones como las del antropólogo Aquiles Escalante, quien en sus ensayos Geoeconomía del algodón (1952) y Geografía del departamento del Atlántico (1961) vio en la gran propiedad territorial dedicada a la ganadería el principal obstáculo para el despegue y fortalecimiento de la producción algodonera de gran demanda en la región costeña ${ }^{11}$.

\footnotetext{
${ }^{9}$ Guillermo Hernández, De los chibchas a la colonia y a la república, Bogotá, eds. Internacionales, 1978; Luís Ospina, Industria y protección en Colombia 1810-1930, Medellín, FAES, 1979; Gerardo Molina, Las ideas liberales en Colombia 1849-1914, Bogotá, Universidad Nacional, 1970; Indalecio Liévano, Los grandes conflictos económicos y sociales de nuestra historia, 2 vols., Bogotá, Tercer Mundo, 1973; Antonio García, Pasado y presente del indio, Bogotá, ed. Centro, 1939; Hernán Toro, "Planteamiento y soluciones del problema agrario", en Darío Mesa et al, Colombia: estructura política y agraria, Bogotá, Estrategia, 1971, pp. 153-219.

${ }^{10}$ Geografía económica de Colombia, tomo IV. Bolivvar, Bogotá, Contraloría General de la República, 1942, pp. 267-288, 291-300; Geografía económica de Colombia, tomo II. Atlántico, Bogotá, Contraloría General de la República, 1936, pp. 98-107.

${ }^{11}$ Informe de los departamentos técnicos en la campaña del primer semestre de 1938, Barranquilla, Granja Experimental Algodonera del Atlántico, 1938; Aquiles Escalante, Geografía del Atlántico, Barranquilla, Imp. Departamental, 1961; Luís E. Osorio, Geografia económica y social de Colombia,
} 


\section{La Nueva Historia}

Un replanteamiento de algunos aspectos de la discusión fue introducido por los economistas e historiadores que por los años de 1960 empezaron a debatir el plan de desarrollo presentado por la misión dirigida por Lauchlin Currie, en especial la propuesta de transformar al latifundio improductivo o dedicado a la ganadería extensiva en complejo agroindustrial $^{12}$. Fue por esta vía que los historiadores de la economía se adentraron en las discusiones sobre la evolución histórica de la tenencia de la tierra y en los estudios sobre las relaciones sociales en el campo colombiano y los vínculos de los diversos agentes sociales con el poder, entre otros temas. Lugar destacado en esas investigaciones lo tuvo los estudios sobre el café, los procesos de ocupación y de poblamiento del territorio colombiano, las investigaciones sobre la violencia que insistían en vincular la protesta social y los levantamientos armados con la estructura de la tenencia de la tierra, los análisis acerca de los procesos de colonización reciente de la frontera agrícola y la protesta social campesina e indígena, el comportamiento del sector exportador de la economía y sus relaciones con la estructura social de las áreas productoras para los mercados internacionales ${ }^{13}$.

Sobresalen quienes inspirados en diversos marxismos pensaban que los análisis debían recaer sobre las formas de propiedad, las formas de producción y el conjunto de relaciones sociales que de ellas devenía, siendo Salomón Kalmanovitz su expositor más acabado ${ }^{14}$. Según esta corriente, desde mediados del siglo XIX la apropiación de los recursos públicos por parte de nuevos hacendados tuvo como fin lograr sujetar una mano de obra escasa e

Bogotá, La Idea, 1941, p. 120; Eduardo Penso, “Aspectos agroeconómicos del Atlántico”, en Revista Geográfica N $\mathrm{N}^{\mathrm{o}}$ 1, Barranquilla, Instituto de Investigaciones Etnológicas-Universidad del Atlántico, 1952; Sergio Paolo Solano, "Familia empresarial y desarrollo industrial en el Caribe colombiano. El caso de la Fábrica de Tejidos Obregón”, en Historia y Cultura N 1, Cartagena, Universidad de Cartagena, 1993, pp. 13-31.

${ }^{12}$ En el informe de esta misión el problema agrario fue entendido en los términos de la irracionalidad económica y técnica aplicada al uso de los suelos del país que destinaba las mejores tierras a la ganadería y las de más difícil acceso a la agricultura, demandando la primera escaso empleo de mano de obra. Entonces, mientras que la mayoría de la población agraria se dedicaba a la agricultura minifundista en condiciones casi primitivas, las mejores tierras se desperdiciaban en la ganadería extensiva. Esto ocasionaba bajos niveles de producción y problemas para el desarrollo industrial. La misión propuso que la solución era transformar las bases técnicas y los usos de las tierras por medio del desarrollo de una agricultura capitalista que no tocara al gran latifundio sino que lo transformara en complejos agroindustriales. La mano de obra excedente expulsada hacia las ciudades debía ser absorbida por el desarrollo industrial urbano. Bases de un programa de fomento para Colombia. Informe de una misión dirigida por Lauchlin Currie, Bogotá, Banco de la República, 1951. Rafael Baquero, "La economía nacional y la política de guerra", en D. Mesa, Colombia: estructura política y agraria, pp. 109-152; Jesús Bejarano, "Currie: diagnóstico y estrategia", en Cuadernos Colombianos No 3, Medellín, La Carreta, pp. 405-434, y "Contribución al debate sobre el problema agrario", pp. 35-38, 50-52.

${ }^{13}$ Jesús Bejarano, Historia económica y desarrollo: la historiografía económica sobre los siglos XIX y XX en Colombia, Bogotá, Cerec, 1994, pp. 116-127, 212-219.

${ }^{14}$ Salomón Kalmanovitz, "Desarrollo capitalista en el campo", en Mario Arrubla (comp.), Colombia hoy, Bogotá, Tercer Mundo, 1977, pp. 257-307; El desarrollo de la agricultura en Colombia, Bogotá, Carlos Valencia eds., 1982; "El régimen agrario durante el siglo XIX en Colombia", en Manual de historia de Colombia, vol. II, Bogotá, Procultura, 1984, pp. 211-324; Economía y nación, Bogotá, Cinep-Universidad Nacional-Siglo XXI eds., 1988, pp. 93-119, 134-168, 193-203 y 206-227. 
insubordinada por efecto del conflicto por la independencia y el mestizaje. Así pues, la hacienda ganadera vino a ser el resultado de la concentración de la riqueza social y del empobrecimiento de amplios sectores del campesinado. Al ser una unidad económica y social que absorbe poca mano de obra el efecto a largo plazo de es e proceso fue una serie de crisis en el orden social y conflictos sociales que desarraigaron al campesinado y lo obligaron a emigrar a los principales centros urbanos, a los puertos y a las áreas de economías agropecuarias más dinámicas. De la misma manera ofrece parecida explicación para el caso del atraso material de la región costeña, atribuido a la ganadería que acapara las más grandes y mejores extensiones de tierra de la Costa, con pocas necesidades de innovaciones tecnológicas y de empleo de mano de obra, que se vio sustraída de la influencia de la economía de mercado, al tiempo que estimuló el desarrollo de instituciones sociales que redujeron a los campesinos a una condición semiservil ${ }^{15}$.

Así, desde distintas perspectivas se fue consolidando el modelo de análisis que vinculaba a la hacienda ganadera con la apropiación de recursos, el poder y la configuración de la sociedad, e insistió en que el factor que distribuyó los recursos y determinó el ordenamiento social fue el poder, mecanismo por medio del cual se accedía a las tierras públicas y se expropiaba a los productores directos sometiéndolos a relaciones semiserviles.

Mientras que los análisis inspirados en este modelo se mantuvieron en el ámbito nacional las conclusiones tendieron a uniformar las lecturas de las relaciones sociales en el agro; pero la apertura a las historias de las regiones empezó a modificar el panorama y muchas de las afirmaciones que generalizaban empezaron a mostrar sus debilidades. Orlando Fals Borda exponente del modelo anteriormente señalado y de las historias regionales, reconoció la diversidad de variaciones regionales y comarcanas que presentaban las relaciones sociales y laborales en campo colombiano ${ }^{16}$. Esa diversidad iban desde sistemas opresivos de sujeción social como era el caso de sectores de jornaleros y "criados domésticos" sometidos a concertaje forzoso (caracterizadas por algunos historiadores como relaciones de servidumbre), pasando por algunos que ataban al campesino a la tierra (aparceros y arrendatarios) y otras en la que el trabajador gozaba de cierta capacidad de decisión (terraje), hasta terminar en las relaciones laborales independientes de los jornaleros agrícolas. Además, las fronteras entre las ocupaciones eran muy laxas, pudiendo una persona desempeñar varios oficios acorde con los periodos productivos, las necesidades de mano de obra y sus intereses.

Por tanto, a una primera imagen rígida de las relaciones socio-laborales, las investigaciones de los años 1980 y 1990, en especial la historiografía regional sobre la economía y la

\footnotetext{
${ }^{15}$ S. Kalmanovitz, Economía y nación, pp. 166-188.

${ }^{16}$ Orlando Fals, Historia de la cuestión agraria en Colombia, Bogotá, La Rosca, 1975; Darío Fajardo, El Estado y la formación del campesinado en el siglo XIX, Bogotá, Cinep, 1981; María T. Uribe y Jesús Álvarez, Poderes y regiones: problemas en la constitución de la nación colombiana 1810-1850, Medellín, Universidad de Antioquia, 1987; Roger Brew, El desarrollo de Antioquia desde la independencia hasta 1920, Bogotá, Banco de la República, 1977, pp. 228-230.
} 
sociedad cafetera, fueron oponiendo otra en la que la estructura social y laboral aparece mucho más fluida en la medida que desde mediados del siglo XIX se fueron resquebrajando las formas de sujeción extraeconómicas impuestas por las haciendas a los trabajadores, los oficios no cristalizaron de manera estable y los trabajadores se desplazaban de unas zonas a otras ${ }^{17}$. Esta variedad de relaciones sociales y de trabajo se combinaba con un campesinado independiente concentrado en poblados (al menos en las investigaciones de Orlando Fals Borda para el caso de la Costa y de Hermes Tovar para el caso del Tolima Grande) que tenía acceso a los bienes nacionales (tierras baldías) y se veía libre de la dependencia aunque acudiera a enganches laborales en ciertas épocas del año. Fals Borda pensó que el mundo social y laboral de los sectores agrarios subordinados iba mucho más allá de la simple dicotomía entre hacendados y campesinos pobres sometidos a relaciones semiserviles, y que en muchas comarcas con las características sociales, económicas y políticas de los territorios de fronteras, donde la ausencia del poder estatal institucional acompañado de un ordenamiento social débil era suplido por formas de poder más informales pero no por ello menos efectivas para acceder a los recursos públicos ${ }^{18}$.

17 Malcolm Deas, "Una hacienda cafetera en Cundinamarca: Santa Bárbara 1870-1912”, en Anuario Colombiano de Historia Social y de la Cultura № 8, Bogotá, Universidad Nacional, 1976, pp. 75-99; Marco Palacios, El café en Colombia, 1850-1970: una historia económica, social y política, Bogotá, El Áncora eds., 1983; Roland Anrup, "Trabajo y tierra en una hacienda andina un análisis de las formas cambiantes de disposición", en Quinto Congreso de Historia de Colombia, Bogotá, Icfes-Universidad del Quindío, 1985, pp. 275-288; Jesús Bejarano, "Los estudios sobre la historia del café en Colombia", en Ensayos de historia agraria colombiana, Bogotá, Cerec, 1987, pp. 83-112; Renzo Ramírez, "De la distribución de baldíos a la consolidación de una región cafetera: dinámica comercial y estructuras agrarias en El Líbano, Tolima, 1886-1897', en Anuario Colombiano de Historia Social y de la Cultura N $^{\circ}$ 26, Bogotá, Universidad Nacional, 1999, pp. 83-114; Formación y transformación de la cultura laboral cafetera en el siglo XX, Medellín, La Carreta Histórica, 2004; Historia laboral de una hacienda cafetera. La Aurora, 1882-1982, Medellín, La Carreta Histórica, 2008; René de la Pedraja, "Los cosecheros de Ambalema: un esbozo preliminar" en Anuario Colombiano de Historia Social y de la Cultura $\mathrm{N}^{\circ}$ 9, Bogotá, Universidad Nacional, 1979, pp. 39-61; Jesús Bejarano y Orlando Pulido, El tabaco en una economía regional: Ambalema siglos XVIII y XIX, Bogotá, Universidad Nacional, 1986; Hermes Tovar, Que nos tengan en cuenta. Colonos, empresarios y aldeas: Colombia, 1800-1900, Bogotá, Colcultura, 1995, pp. 138-201; Catherine LeGrand, "Campesinos y asalariados en la Zona Bananera del Magdalena 1900-1935", en Anuario Colombiano de Historia Social y de la Cultura No 11, Bogotá, Universidad Nacional, 1983, pp. 235-250; Gloria I. Ocampo, "Hacienda y campesinos en el Sinú: Formas de vida y formas de trabajo en 'Marta Magdalena' (1912-1954)", en Museo del Oro No 20, Bogotá, Banco de la República, 1988, pp. 112-119; José Polo, "La población rural del Caribe neogranadino durante el siglo XVIII: ¿Potencial mano de obra para una agricultura de plantación?”, en Alberto Abello (comp.), Un Caribe sin plantación, San Andrés, Universidad Nacional-Observatorio del Caribe Colombiano, 2006, pp. 125-139.

${ }^{18}$ O. Fals, Capitalismo, hacienda y poblamiento en la Costa Atlántica, Bogotá, Punta de Lanza, 1975; "Influencia del vecindario pobre colonial en las relaciones de producción de la Costa Atlántica colombiana", pp. 156-160; Resistencia en el San Jorge, Bogotá, Carlos Valencia eds., 1984; Retorno a la tierra, Bogotá, Carlos Valencia eds., 1986. Hermes Tovar, Grandes empresas agrícolas y ganaderas, Bogotá, Ciec, 1980; "Los baldíos y el problema agrícola en la Costa Caribe colombiana (1830-1900)", en Fronteras N N 1, Bogotá, Instituto Colombiano de Antropología, 1997, pp. 35-55; C. LeGrand, "De las tierras públicas a las propiedades privadas: acaparamiento de tierras y conflictos agrarios en Colombia 1870-1930", en Lecturas de Economía No 13, Medellín, Universidad de Antioquia, 1984, pp. 13-50; Colonización y protesta campesina en Colombia 1850-1950, Bogotá, Universidad Nacional, 1988, 112 119; Hugues Sánchez, "El surgimiento de una economía campesina: poblamiento y mercados locales en el Bajo Magdalena”, en Colombia y el Caribe XIII ${ }^{\circ}$ Congreso de colombianistas, Barranquilla, Universidad del Norte, 2003, pp. 71-83; "Tendencias y problemas en la historia del Caribe colombiano", en Historia y Pensamiento No 3, Barranquilla, Universidad del Atlántico, 1999, pp. 73-74; H. Sánchez y Adriana Santos, "Dos casos de colonización y expansión de la frontera agrícola en la gobernación de Santa Marta

El Taller de la Historia, vol. III, $N^{\circ}$ 3, 2011, págs. 161-188. Issn: 1657-3633

Programa de Historia, Facultad de Ciencias Humanas, Universidad de Cartagena de Indias, Colombia 
La diversidad de análisis, de los modelos aplicados, las fuentes informativas empleadas y los intentos de generalizaciones interpretativas fueron sometidos a un riguroso balance historiográfico por parte del malogrado Jesús A. Bejarano, quien presentó una agenda completa para el estudio de la llamada cuestión agraria ${ }^{19}$. Según él, el estudio de ese tema en general y de la hacienda en particular exige analizar las formas de apropiación de los recursos y como se organiza la producción, es decir, las relaciones de trabajo. Conocedor detallado del problema agrario nacional, este historiador propuso una agenda investigativa que resalta la necesidad de estudiar los aspectos directamente vinculados con la producción (técnicas, métodos, instrumental, plantas, crías, etc.); las formas de apropiación y de uso del suelo, organización de las unidades productivas (haciendas, plantaciones, parcelas); las formas de organización de la fuerza de trabajo (estatus social y jurídico de los trabajadores como la esclavitud, servidumbre, trabajadores asalariados). De igual manera demandó que esto se llevara a cabo teniendo siempre presente la necesidad de mayores precisiones acorde con los contextos, periodos y regiones (provisión y movilidad de la mano de obra, formación del mercado laboral, arrendamiento, peonaje, mano de obra libre, etc.). También sugirió reemplazar las vagas hipótesis acerca del impacto de las reformas liberales en la formación del mercado de trabajo, con mayores precisiones, cuantificaciones y especificidades regionales.

En esta misma dirección criticó la diversidad de interpretaciones que estudiaban los orígenes del campesinado a partir de la disolución de las instituciones coloniales sobrevivientes en el siglo XIX como la esclavitud y los resguardos indígenas. Para Bejarano la hacienda como concepto genérico “... designa una unidad de producción que se caracteriza tanto por su dimensión, como por una organización interna fundada en diversos métodos de coerción extraeconómica sobre la fuerza de trabajo. Como [tal] sirve para definir estos rasgos pero habría que precaverse de hacer equivalente en sus contenidos este concepto para todas las épocas y todas las regiones". Este es un problema clave que necesita ser investigado como también el de la periodización de la hacienda y su influencia en la vida social y política del siglo XIX y hasta 1930, pues “... sin esas dos claves, evolución [de la hacienda] y poder rural, sería en rigor difícil enfrentar una verdadera historia agraria nacional”. Sin tener presente estos factores no puede explicarse la dinámica de la cuestión agraria expresada en descomposición campesina, formación del trabajo asalariado, generalización de la economía de mercado, concentración de la riqueza, el papel del Estado, en fin, el tránsito al capitalismo.

en la segunda mitad del siglo XVIII: San Sebastián de Rábago y Santa Cruz de Pizarro”, en Historia Caribe $\mathrm{N}^{\mathrm{o}}$ 8, Barranquilla, Universidad del Atlántico, 2003, pp. 101-114.

19 J. Bejarano, "Reflexiones sobre el carácter epistemológico de la investigación en el sector agrario" e "Historia, desarrollo y verificación", en Encuentros nacionales de investigadores universitarios en ciencias económicas, Bogotá, Icfes, 1980-1984, pp. 33-43 y 109-126. 


\section{Los estudios sobre la hacienda y la ganadería en la región Caribe colombiana}

Ahora bien, para el caso específico de la región Caribe colombiana y en el marco de lo que se ha dado en llamar la Nueva Historia, los estudios sobre la hacienda y la economía ganadera son muy recientes y desiguales, siendo los más significativos los de Hermes Tovar, Orlando Fals, Adolfo Meisel y Alejandro Reyes Posada.

En 1980 Hermes Tovar publicó su libro Grandes empresas agrícolas y ganaderas dedicado al estudio de la hacienda en algunas áreas del Nuevo Reino de Granada durante la segunda mitad del siglo XVIII, reeditado seis años después con correcciones y ampliaciones en el tratamiento de algunos temas bajo el nombre de Hacienda colonial y formación social. Con el rigor que caracterizan sus trabajos y con base en algunos estudios de haciendas y hacendados andinos y costeños del siglo XVIII, H. Tovar llamó la atención para que el estudio de la hacienda avanzara más allá del análisis de los mecanismos de apropiación de las tierra, y que las relaciones socio-laborales que contenía debía superar ciertas simplificaciones de los mecanismos de explotación y de extracción de los excedentes económicos. Contrario a la creencia en boga entre algunos historiadores que achacaban a la hacienda ser una explotación totalmente irracional (verbigracia, S. Kalmanovitz), Tovar demostró que esta unidad económica y social debía estudiarse como una empresa que poseía su propia racionalidad económica que llevaba al hacendado a calcular sus inversiones en concordancia con los ciclos económicos de los mercados locales y comarcanos, y que las ocupaciones de tierras respondían a las necesidades de unas tecnologías de explotación del suelo de carácter extensivas. También señaló que el empleo del trabajo lo hacía siguiendo las fases de la producción y el cálculo de la rentabilidad, y que en consecuencia la mano de obra podía ser muy fluida. De igual manera estableció diferencias en el empleo de mano de obra entre las haciendas de caña de azúcar y las ganaderas empleando las primeras mayor cantidad de esclavos y las segundas trabajadores libres. Que en la segunda mitad del siglo XVIII las relaciones socio-laborales se hicieron laxas y con una creciente tendencia a la generalización del trabajo libre estacional. En sus propios términos, "La aparición de un nuevo tipo de empresa y empresario en el siglo XVIII, sustentó su crecimiento sobre la crisis de la hacienda basada en mano de obra servil y sobre el nacimiento de la mano de obra libre asalariada" ${ }^{20}$.

En esta corriente crítica frente a las consecuencias históricas de la economía ganadera en la Costa Caribe sobresalen las reflexiones de Adolfo $\mathrm{Meisel}^{21}$, en quien podemos distinguir

${ }^{20} \mathrm{H}$. Tovar, Grandes empresas agrícolas y ganaderas, 13-14; "Algunos aspectos de la sociedad rural en Colombia (siglos XVIII-XIX)", en Historia económica de Colombia. Un debate en marcha, Bogotá, Instituto de Estudios Colombianos-Banco Popular, 1979, pp. 91-122.

${ }^{21}$ Adolfo Meisel, "Los estudios sobre la historia económica de Colombia a partir de 1990: principales temáticas y aportes", en Cuadernos de Historia Económica y Empresarial No 13, Cartagena, Banco de la República, 2005, pp. 37-38; “¿Por qué perdió la Costa el siglo XX?”, en Haroldo Calvo y Adolfo Meisel (eds.), El rezago de la Costa Caribe colombiana, Cartagena, Banco de la República-FundesarrolloUniversidad del Norte-Ujtl, 1999, pp. 69-102; “¿Por qué se disipó el dinamismo industrial de Barranquilla?", en Lecturas de Economía No 23, Medellín, Universidad de Antioquia, 1987, pp. 57-84; "Esclavitud, mestizaje y haciendas en la Provincia de Cartagena 1533-1857”, en Gustavo Bell (comp.), El 
dos etapas relacionadas. La primera se corresponde con su interés en los estudios macro de las relaciones entre las economías urbanas y agrarias de la región Caribe colombiana para develar en que medida el sector industrial costeño no halló condiciones favorables para su crecimiento en el mercado regional debido a las relaciones económicas y sociales predominantes en el campo de esta región. La segunda fase se corresponde con los últimos años en que Meisel y el equipo de investigadores que le acompaña han descendido a los niveles de estudios de casos de historias empresariales para intentar reconstruir de manera más exhaustiva el desarrollo económico de esta región durante los siglos XIX y XX.

Durante la primera fase Meisel se basó en modelos teóricos propios de su formación profesional de economista y sociólogo que pretenden explicar las tendencias y limitaciones del desarrollo, relacionando las áreas económicas y comparando con la economía de otras regiones y la nacional. Su idea central puede formularse de la siguiente manera: en el siglo XIX y primera mitad del XX el éxito de la fase inicial del crecimiento económico de una región y/o país dependía de la inserción satisfactoria en los mercados internacionales del sector agroexportador, mientras que las posibilidades de crecimiento del sector que producía para el mercado interno dependía tanto de su comercialización interna como del comportamiento sector exportador. Por tanto, por el mismo carácter del modelo agroexportador las regiones que se especializaron en la producción para exportar crecieron, mientras que las vinculados a la economía nacional interior se estancaron: "tanto el ritmo como el carácter del crecimiento económico de una región están determinados por el éxito de su sector exportador, por las características de éste y por la forma como se gasta el ingreso que él genera",22.

Ante la pregunta sobre el fracaso del sector exportador de la Costa Caribe en el periodo 1905-1950, precisamente cuando el país vivió la etapa más exitosa en este campo en toda su historia económica, Meisel ha diseñado varias hipótesis propia de su interés en el enfoque del tipo de eslabonamientos desarrollada por Albert Hirschman que relaciona el impacto del crecimiento económico en las diversas áreas económicas, con la sociedad y las políticas gubernamentales. Una señala que el eslabonamiento que existió entre el desarrollo industrial urbano y la economía agraria no era el más adecuado para que aquél mantuviera su crecimiento al ritmo del resto del país, pues al especializarse la segunda en la producción ganadera vinculada al mercado interno, actividad que demandaba poca mano de obra, el mercado regional costeño era restringido, y en consecuencia la producción industrial no podía sostener su crecimiento. También se debió al carácter portuario y comercial de sus principales ciudades, que por factores que se remontan a la colonia y que aún no se han estudiado (la región nunca fue escenario de una economía agrícola fuerte, y desconoció la economía de plantaciones como si las tuvieron otras áreas de la cuenca del Caribe), y por el modelo económico agroexportador, crecieron de espaldas a sus hinterland

Caribe colombiano. Selección de textos históricos, Barranquilla, Universidad del Norte, 1988, pp. 69-138; "Prólogo" a Remberto Burgos, El general Burgos, Cartagena, Gobernación de Bolívar-Universidad de Cartagena, 2000, pp. 13-18.

${ }^{22}$ A. Meisel, “¿Por qué perdió la Costa el siglo XX?”, pp. 69-102. 
naturales y no se convirtieron en motor de transformaciones en el campo como si sucedió en otras latitudes.

Caso contrario el de otras regiones que durante la primera mitad del siglo XX estaban ligadas a los mercados internacionales o dominaban la producción de uno o varios sectores para el tráfico interior, lo que suponía economías más fuertes como la cafetera en la zona de colonización antioqueña, y la agroindustria azucarera y con un puerto en alza como lo era Buenaventura, en la región del Valle del Cauca. Por tanto, allí los nexos entre las economías urbanas y rurales favorecían al establecimiento de industrias. El asunto en la Costa era un poco diferente pues la ganadería llevó a “... la enorme desigualdad en la propiedad de la tierra ha sido la causante de una distribución del ingreso altamente inequitativa." En contrapunto con la ganadería Meisel presenta el caso del algodón al que considera un producto agrícola más beneficioso para el desarrollo del campo porque demandaba mayor empleo de mano de obra. El fracaso de este renglón agrícola se debió a las políticas comerciales y cambiarias del gobierno central que facilitaron a los industriales textileros importar insumos a costa de la producción nacional, lo que se hubiese podido salvar asignando cuotas a los importadores, aumento de aranceles, etc. Todo esto se le achaca a la falta de presencia decisoria de la Costa en las decisiones políticas del Estado central.

Años después volverá a afirmar lo mismo, pero desde una perspectiva que mira los efectos de ganadería en el grado de inserción de la economía costeña en la nacional, y en qué medida los efectos macroeconómicos del auge de las exportaciones cafeteras, tuvieron esos efectos "perversos" de condenar a buena parte del país al estancamiento y el atraso, al tener que especializarse para los mercados internos.

Infortunadamente para la Costa Caribe, el bien para el cual tenía ventajas comparativas y al cual mejor se adaptó su dotación natural de recursos, el ganado vacuno, tiene una elasticidad ingreso menor que uno. Por lo tanto, el producto que se convirtió en el motor de crecimiento de las zonas rurales de la Costa en el siglo XX tenía limitaciones estructurales que hicieron que la región creciera menos que el resto del país... ni el grado de encadenamientos de la ganadería costeña era favorable para el desarrollo de la región ni las características de demanda de la carne (elasticidad ingreso menor que uno) le permitían ser un vigoroso motor de desarrollo regional. Sobre esto último no se percató Posada, al no haber analizado la economía costeña desde el punto de vista de su producto interno bruto (PIB) total y en términos comparativos con la economía del resto del país ${ }^{23}$.

El atraso de la Costa se produjo en el siglo XX, pues en la centuria anterior esta región presentaba índices per cápita del PIB parecidos o ligeramente inferiores al resto del país, y se debió, y esta es su tesis central, al fracaso del sector exportador regional durante las primeras décadas del siglo XX. El pésimo desempeño del sector exportador llevó a que la

${ }^{23}$ A. Meisel, “¿Por qué perdió la Costa el siglo XX?”, pp. 69-102. 
Costa entrara a la segunda mitad de ese siglo en condiciones desventajosas para competir con las demás.

En este punto nuevamente se empatan las miradas de Meisel con los historiadores antes señalados, en la medida que consideran que el impacto que esto tuvo en la formación del mercado regional costeño fue desastroso si se le compara con el caso de la industria antioqueña que contó con el fuerte mercado del territorio de la colonización paisa, con cierto poder adquisitivo gracias a la economía cafetera de pequeños, medianos y grandes caficultores. Atados a la tierra y a diversas formas de sujeción social, el mercado de fuerza laboral se vio afectado. A su vez, la demanda inelástica de los productos de las economías urbanas no favoreció la formación de un fuerte mercado regional costeño, y esto, en una secuencia encadenada, afectaba las posibilidades de desarrollo del incipiente sector manufacturero e industrial costeño de comienzos del siglo XX, en la medida en que el destino de su producción, los mercados de la región, carecían de esa generosidad en la demanda. Además, se considera por estos investigadores que la dedicación de la mayoría de las mejores tierras a la ganadería, afectaba las posibilidades del incremento de la producción agraria de productos alimenticios y materias primas, lo que se dejaba sentir en el alto costo de vida de las principales ciudades de la región.

En la segunda fase de sus estudios Meisel (y quienes le acompañan) ha puesto el énfasis en los estudios de casos de los empresarios más significativo de la Costa, muchos de estos hacendados ganaderos como era lo usual ${ }^{24}$. El propósito está dirigido a la reconstrucción puntual de las principales esferas del mundo empresarial costeño, tanto por el interés en develar relaciones entre las economías agraria e industrial y comercial, como por ver la racionalidad económica que rige a la política de inversiones de los empresarios ${ }^{25}$. En el caso específico de la ganadería, Meisel y el equipo de investigación de historia empresarial del Banco de la República, han señalado que su racionalidad estuvo determinada por las características de la "dotación natural de los factores productivos" (suelos y clima) ${ }^{26}$.

\section{Historiografía revisionista. La obra de Eduardo Posada}

El referido cuerpo de ideas que contaba con cierto consenso generalizado en los medios académicos, intelectuales y políticos de la región caribeña, en estos últimos años ha recibido el desafío de la obra del historiador Eduardo Posada, la que representa una invitación a explorar el mundo de la ganadería y a volver a pensar acerca de las

${ }^{24}$ A. Meisel y Joaquín Viloria, "Los alemanes en el Caribe colombiano: el caso de Adolfo Held, 18701927”, en Cuaderno de Historia Económica y Empresarial No 1, Cartagena, Banco de la República, 999, pp. 43 y ss.; J. Viloria, "Ganaderos y comerciantes en Sincelejo, 1880-1920, en Cuaderno de Historia Económica y Empresarial № 8, Cartagena, Banco de la República, 2001; María T. Ripoll, Empresarios centenaristas en Cartagena. Cuatro casos de estudio, Cartagena, Universidad Tecnológica de BolívarUniversidad de los Andes, 2008.

${ }^{25}$ A. Meisel, "Prólogo", pp. 13-18.

${ }^{26}$ A. Meisel, "Puertos vibrantes y sector rural vacío: el Caribe neogranadino a finales del periodo colonial”, en A. Abello, Un Caribe sin plantación, pp. 96-97. 
implicaciones económicas, sociales y políticas de ese sector productivo en todos los órdenes del desarrollo regional.

Posada ha sacado la investigación del campo de las relaciones sociales y la ha llevado al terreno del mercado para así determinar los factores que favorecieron, frenaron e imposibilitaron el crecimiento económico del Caribe colombiano. Se trata de una nueva mirada exploradora aspectos económicos y sociales que ha producido un cuadro mucho más complejo de la sociedad agraria costeña que el que acostumbramos a imaginarnos. El modelo que emplea no se centra en la organización social que surge de la apropiación de los recursos y de la producción, sino en la circulación y distribución de la riqueza social y la reinversión de los excedentes económicos que generaba. Por eso, estudia temas como la poca población que encarecía el costo de la mano de obra, los enormes recursos de tierras públicas que imposibilitaban introducir mejoras en el utillaje de trabajo, las escasas y precarias vías de comunicación, unidas a periódicas condiciones climáticas adversas y a los problemas que se presentaban por la escasez y los riesgos en la inversión de capitales en el campo costeño. Entonces, más que interesarse en explicar el atraso agrario que tanto ha cautivado a quienes contradice, el modelo que emplea Posada lo lleva a privilegiar como objeto de investigación los ensayos empresariales que se hicieron en ese sector y las limitaciones que hallaron para su desarrollo, lo que sin duda es un buen síntoma pues saca la discusión del terreno de las generalidades y la lleva al de la peculiaridades del desarrollo empresarial agrario costeño, que es uno de los frentes que debe abocar la investigación de la cuestión agraria ${ }^{27}$.

En su modelo se concibe al crecimiento demográfico y comercial y a la economía de mercado, como los elementos que dinamizaron el tránsito de la región costeña a la sociedad moderna. Así, un crecimiento sostenido de la población llevó a una presión muy fuerte sobre los recursos naturales, desatando una competencia en el espacio comercial que terminó por acarrear su concentración en pocas manos. Por tanto, para esta interpretación la clave para explicar ese tránsito es el mercado, en el que se distribuye y se accede a la riqueza mediante el libre juego de individuos que compiten, generando un proceso que termina por concentrar la riqueza en unos pocos a través de esa movilidad social por la competencia que “... implicaba el ascenso de unos y la caída de otros"28.

Desde esta perspectiva este historiador objeta a la interpretación de la Nueva Historia sobre la economía agraria del siglo XIX varias debilidades, imprecisiones y equivocaciones. En primer lugar observa, con toda razón, que las afirmaciones de aquella corriente no están fundamentadas en una suficiente exploración de la información ni en estudios de casos acerca de las formas de propiedad territorial, en especial de la hacienda ganadera, como también de las relaciones sociales que se desarrollaron en su interior, ni en las economías campesinas y de sus vínculos con la economía ganadera. Por tanto, se trata más de

27 Eduardo Posada, El Caribe colombiano una historia regional (1870-1950), Bogotá, Banco de la República-El Ancora eds., 1997, pp. 142 y ss.

${ }^{28}$ E. Posada, “La ganadería en la Costa Atlántica colombiana, 1870-1950”, en Coyuntura Económica vol. XIII, No 3, Bogotá, Fedesarrollo, 1988, p. 149. 
conjeturas devenidas de modelos extrapolados que suponen a la ganadería en ascenso enfrentada a la agricultura a la que terminó arruinando, desconociendo que la combinación de factores como el medio natural costeño, los recursos materiales y humanos y la carencia de capitales llevaron al fracaso de las pocas empresas agrícolas que se plantaron en la región, con excepción de la economía bananera del Magdalena.

También objeta la imagen que asocia al campo costeño a una bipolaridad social de hacendados-campesinos pobres pues no se atiene a la realidad del intrincado negocio de la ganadería que suponía una especialización acorde con las fases de producción, que involucraban a pequeños y medianos ganaderos. De igual forma, rechaza la idea que supone la existencia de relaciones sociales semiserviles en el campo, pues están en contravía con las conclusiones de los estudios de casos realizados como los de Orlando Fals Borda sobre el vecindario pobre libre, el de Hermes Tovar Pinzón sobre la hacienda costeña del siglo XVIII y otros sobre algunas haciendas en los siglos XIX y XX, trabajos que antes de demostrar la existencia de relaciones serviles señalan lo contrario, la existencia de una tendencia creciente de mano de obra libre.

En consecuencia, Posada propone una nueva interpretación en la que resalta la exploración de la racionalidad económica que subyace a la apropiación de grandes porciones del suelo, la especialización de las diversas fases de la producción vacuna que estimula la participación de pequeños y medianos ganaderos, sus aportes al desarrollo de la economía regional y nacional y la manera como se irradió la riqueza entre los diversos sectores económicos que participaron en ese renglón económico. Se trata de una nueva y sugerente mirada que explora aspectos económicos y sociales que da como resultado un cuadro mucho más complejo de la sociedad agraria costeña que el que acostumbramos a imaginarnos. Entonces, más que interesarse en explicar el atraso agrario que tanto ha cautivado a quienes contradice, el modelo que emplea Posada lo lleva a privilegiar como objeto de investigación los ensayos empresariales que se hicieron en ese sector y las limitaciones que hallaron para su desarrollo, lo que sin duda es un buen síntoma pues saca la discusión del terreno de las generalidades y la lleva al de la peculiaridades del desarrollo empresarial agrario costeño, que es uno de los frentes que debe abocar la investigación de la cuestión agraria ${ }^{29}$.

Corriendo riesgos podemos resumir el cuerpo de ideas de este historiador de la siguiente manera:

1. La satanización de la hacienda tiene antecedentes en una vertiente de carácter liberal decimonónica que estableció una relación entre el dominio político conservador y eclesiástico sobre amplio sectores de la población campesina, las formas de sujeción de la mano de obra y la gran propiedad territorial. Los liberales de las reformas de mediados del siglo XIX, habían heredado algunas lecturas de las críticas de los economistas ingleses y franceses a los fisiócratas, ahora enriquecidas con los economistas ingleses del siglo XVIII.

${ }^{29}$ E. Posada, El Caribe colombiano una historia regional, pp. 142 y ss. 
Estos pensadores ligaron la hacienda y el latifundio a formas de poder local, comarcano y regional, en concreto al dominio de la iglesia y del partido conservador en las zonas agrarias.

2. Los tres factores que estimularon la inversión en la ganadería al mismo tiempo se encargaron de imponer limitaciones a su ulterior desarrollo. Según Posada, la escasez de capitales para invertir en una agricultura intensiva o en agroindustrias; las dificultades de la geografía que imposibilitaba crear un mercado de productos agrícolas dados los problemas del transporte, por lo que movilizar el ganado se facilitaba, pero con un enorme costo por la pérdida de peso de las reses; y por último la escasez de mano de obra que encarecía su contratación. Pero al tiempo que estos factores impulsaron en desarrollo de la ganadería que requería poca inversión de capital, disponía de recursos públicos que podían ser apropiados o utilizados, demandaba poca mano de obra, y cierta facilidad de movilización del ganado en pie hacía las zonas de consumo, limitaron el posterior desarrollo de esa industria. Para resumir la idea central en palabras del autor, “... fueron las condiciones desventajosas del mercado de la región -incluyendo su geografía- las que explican mejor el desarrollo ganadero." Frente a un medio natural que limitaba la estabilidad espacial de la industria ganadera, y ante las modestas fortunas de los empresarios, la ganadería extensiva fue la que mejor se adecuó a las condiciones naturales, demográficas, económicas y sociales de los valles y las llanuras ganaderas de la región Caribe.

3. Para sacar el estudio de la ganadería del purgatorio en que ha estado condenada, hay que empezar por reconocer que se trataba de una labor empresarial con un alto grado de racionalidad, y cuyos actores son muchos más que la simple bipolaridad terratenientescampesinos, idea planteada por Catherine LeGrand en su crítica a las tesis sobre un empresariado de corte tradicional y por ende carente de racionalidad ${ }^{30}$. En el desarrollo de esta actividad económica intervinieron diversos estratos de la población rural y urbana costeña por medio de una especialización de labores en concordancia con las distintas fases de la vida del ganado (cría, levante y engorde), moviendo gruesas sumas de capitales; también estaban los propietarios de tierras que las arrendaban a ganaderos, los intermediarios y comerciantes en ganado, quienes recibían en sus tierras ganado "al tercio" o "terciadores" que en el negocio se llevaba el 30\% de la producción del ganado que estuviese bajo su custodia. Por tanto, no siempre existieron vínculos directos entre la condición de ganadero y de poseedor de tierras y a la inversa. También existieron formas de propiedad territorial y ganaderas alternas al latifundio: pequeñas y medianas propiedades de ganaderos criadores o de arrendadores de tierras y pastos; tierras comunales en forma de ejidos municipales, proindivisos, resguardos, tierras baldías. Todo esto estuvo acompañado con la existencia de un activo mercado de tierras que llevaba a que la gran propiedad territorial no se consolidara, y a que el hato ganadero circulara intensamente entre las fases extremas de nacimiento, cría, levante, engorde y consumo final.

${ }^{30}$ C. LeGrand, Colonización y protesta campesina en Colombia 1850-1950, pp. 61-69. 
4. De lo anterior se colige que el mundo agrario costeño era mucho más complejo y dinámico en su estructura social de lo que hasta ahora nos hemos imaginamos. La relación ganadería, economía y sociedad implica la existencia de economías campesinas y ganaderas y de economías pastoriles, un significativo número de pequeños y medianos propietarios, la existencia de intermediarios en el mercado ganadero, todo esto al lado de los hacendados, ganaderos y de los propietarios de ganados más no de tierras. Por tanto, la sociedad agraria costeña estaba lejos de esa visión dual del terrateniente ganadero y el campesino pobre sometidos a relaciones serviles. También intervenían, además de los mencionados, los transportadores, los propietarios de tierras y pastos más no de ganados que lucraban el negocio del arriendo de las tierras, y los campesinos desposeídos que arrendaban tierras bajo diversas modalidades. Al lado de la hacienda existieron otras formas de propiedades territoriales y ganaderas como las pequeñas y medianas propiedades de ganaderos criadores o de arrendadores de tierras y pastos; tierras comunales en forma de ejidos municipales, proindivisos, resguardo, tierras baldías. Es pues, una sociedad mucho más compleja de lo imaginado, y la actividad ganadera se erige sobre una división regional y técnica del trabajo. Desde estas perspectiva se achaca de inconsistente la tesis que sostiene una supuesta generalización de relaciones sociales serviles y semiserviles en el campo costeño, idea que representa uno de los puntos fuertes de sus contradictores. Por otra parte la existencia de un activo mercado de tierras que llevaba a que la gran propiedad territorial no se consolidara, y a que el hato ganadero circulara intensamente entre las fases extremas de nacimiento, cría, levante, engorde y consumo final ${ }^{31}$.

5. El estudio de las relaciones sociales en el campo costeño puede llevarse a cabo asumiendo como punto de partida la condición libre de la mayoría del campesinado con un alto sentido de independencia y autoestima. Observaciones de viajeros que recorrieron la región costeña, una voluminosa información de archivos nacionales y extranjeros, y algunas hipótesis de Orlando Fals Borda acerca de la laxitud de las relaciones sociales costeñas (debido a la escasa presencia de los mecanismos institucionales como el Estado y la iglesia, la forma de ocupación del territorio con un predominio del poblamiento disperso, y la incomunicación por ausencia de vías, por la geografía y por los intensos periodos de lluvia), permiten a E. Posada proponer la tesis de que la precaria cohesión social dio pie para que las relaciones sociales costeñas se caracterizaran por la insubordinación y la altivez de sus habitantes frente a toda forma de control, actitudes facilitadas por el hecho de que podían satisfacer sus necesidades con los recursos que la naturaleza les ofrecía para así no tener que rendirle cuenta a nadie. En consecuencia, el tipo de relaciones sociales que se desarrollaron en esta región no estuvieron marcadas por el predominio de sujeción servil como han sugerido otros historiadores, y como sí parece ser el caso de otras regiones colombianas. Además, la constante escasez de mano de obra que padeció la región a lo largo del siglo XIX y la disponibilidad de recursos naturales, eran factores que estaban en contravía de la posibilidad de esa forma de subordinación social; todo lo contrario, el control de la oferta laboral permitió a los trabajadores imponer condiciones como el

${ }^{31}$ E. Posada, "Empresarios y ganaderos en la Costa Atlántica (1850-1950)", en Carlos Dávila (comp.), Empresas y empresarios en la historia de Colombia. Siglos XIX-XX, tomo I, Bogotá, Norma-CepalUniandes, 2003, pp. 61-81. 
adelanto de parte del jornal, a lo que -según Posada- no se le puede achacar el carácter de una esclavitud por deudas.

6. Si independencia, insubordinación, acceso a los recursos naturales públicos y la baja densidad demográfica explican la constante penuria de mano de obra que enfrentaron las haciendas ganaderas, las formas modernas de la economía agropecuaria y los incipientes ensayos fabriles costeños del tránsito del siglo XIX al XX, la superación de esta situación se debió, por un lado a la presión que ejerció el crecimiento demográfico sobre la disponibilidad de recursos naturales, quitándole a grandes sectores de la población la posibilidad de continuar llevando una vida independiente, y por otra parte a la expansión de la economía de mercado que originó una competencia por los recursos productivos en la que se vieron involucrados diversos actores no tanto como conglomerados sociales sino como sujetos individuales. Este es uno de los argumentos centrales de este historiador en torno al tema del tránsito al capitalismo. Vale la pena citarlo textualmente: "El cercamiento de las fincas y la expansión de la ganadería seguramente produjeron enfrentamientos con las economías campesinas y con muchos poseedores de ganado sin títulos sobre la tierra. Este acomodamiento necesita de estudios más detallados con el fin de conocer sus complejidades y las diversas soluciones a que dio lugar. Ciertas familias tradicionales consolidaron su posición entre los grandes ganaderos de la región, como los Martínez, los Piñeres y los Vélez. Hubo al tiempo muestras significativas de movilidad social... Esta... implicaba el ascenso de unos y la caída de otros" ${ }^{\text {"32. }}$.

7. La competencia por los recursos productivos comenzó en pleno con el incremento de la demanda de ganado por parte de los mercados centroamericanos y del Caribe (a partir de la Guerra de los diez Años en Cuba, 1868-1878), del mercado antioqueño y parte de los santanderes, como también con el crecimiento de la población costeña. Frente a quienes achacan el atraso económico de la Costa a la ganadería extensiva que dio origen a los grandes latifundios, Posada descubre en esta necesidad de cercar y acaparar grandes extensiones de tierras y otros recursos productivos como era el ganado cimarrón y la provisiones hídricas, el hecho de que la actividad ganadera se desarrollaba en una región de llanuras aluviales sometidas a intensos periodos de inundaciones y de sequías que obligaban a movilizar constantemente los hatos ganaderos acorde con la provisión de aguas y de pastos. Los mayores beneficiados fueron los hacendados, seguidos por los medianos y pequeños campesinos, que se apropiaron de parte de los recursos públicos mediante la colonización de la frontera agrícola. En sus propias palabras, “... las presiones demográficas y el desarrollo de una economía de mercado impusieron crecientes limitaciones al uso de los recursos, mientras determinaban nuevos patrones de relaciones sociales" $" 33$.

\footnotetext{
${ }^{32}$ E. Posada, "La ganadería en la Costa Atlántica colombiana, 1870-1950”, p. 149.

${ }^{33}$ E. Posada, "Progreso y estancamiento1870-1950", en Adolfo Meisel (comp.), Historia económica y social del Caribe colombiano, Barranquilla, Universidad del Norte, 1994, p. 265.
} 
8. Por todo esto, más que ser un factor que obstaculizó el desarrollo económico y social de la Costa, la ganadería extensiva manifestaba una racionalidad económica que involucraba a los hacendados y de manera complementaria a los medianos y pequeños propietarios, mediante la organizaron de una especialización de las actividades entre la cría, el levante, el engorde y la saca de reses con sus respectivos circuitos de tráfico mercantil que les permitían vivir de una forma complementaria. Esto también dio pie a una intensa comercialización de la tierra, a la formación de haciendas por la compra de medianas y pequeñas propiedades, como también a la inversa, a la fragmentación de las primeras en medianas y pequeñas propiedades ${ }^{34}$.

9. Han sido significativos los aportes de la ganadería al proceso de industrialización de la Costa, tanto por el empleo de los subproductos como cueros y sebos en curtiembres, talabarterías, fábricas de zapatos y jabonerías, como por los capitales que algunos hacendados trasladaron del área rural a la economía industrial y agroindustrial ${ }^{35}$. Todo esto implicó la existencia de una racionalidad empresarial moderna entre los hacendados y ganaderos, en la que estuvo presente una alta adaptación a un medio de llanuras aluviales de clima tropical, y sometidas a la alternancia de periodos de intensas lluvias y fuertes sequías.

Estamos pues, frente a un nuevo discurso historiográfico rico en hipótesis y sugerencias, cuya primera consecuencia ha sido cuestionar las imágenes que teníamos sobre el tema y proponer una lectura alterna y más compleja del mismo, con un mayor énfasis por el lado de los aportes de la ganadería al desarrollo económico regional. Aspectos como la propiedad territorial, las relaciones sociales y la compleja red de sectores sociales que van más allá de la dicotomía hacendado-campesino pobre, la existencia de una racionalidad económica acorde con los periodos del clima que explica la necesidad de significativas extensiones de tierras por parte de los hacendados, la existencia de un significativo mercado de tierras y de ganado, representan parte de una agenda investigativa planteada por este historiador, la que debe ser recogida y debatida sana y desprevenidamente.

\section{Críticas a la interpretación de Eduardo Posada}

Ahora bien, aunque la obra de Posada obliga a replantear algunos aspectos de la interpretación "antilatifundista sociológica", a continuación presento algunos puntos discrepantes de sus opiniones. En primer lugar señalemos que los aspectos sociales de la región no los trata con la intensidad con que estudia los temas del desarrollo económico moderno. Algo parecido acontece con el aspecto de la política (o del poder) visto sólo en sus manifestaciones institucionales (Estado, iglesia, partidos) y en las relaciones de los grupos de poder de la región con el Estado central, pero con ningún interés en el tema de las relaciones entre el poder, la sociedad y el periodo de acumulación de capitales que se

34 E. Posada, “La ganadería en la Costa Atlántica colombiana, 1870-1950”, pp. 143-175.

35 E. Posada, “La ganadería en la Costa Atlántica colombiana, 1870-1950”, pp. 143-175. 
vivía. Por eso, un elemento que se echa de menos en su obra es que el estudio del desarrollo de la economía y de la sociedad costeña no está atravesado por las mediaciones del poder. Existen insinuaciones y conjeturas al señalar que la economía ganadera generó conflictos sociales, pero sin mayores explicaciones dado que no es un tema de sus preocupaciones.

Creemos que unas debilidades de la argumentación central de este historiador sobre la racionalidad económica de la ganadería en un contexto ambiental adverso, con escasez de capitales, de mano de obra y de vías de comunicación radica en detener su indagación en un aspecto clave que esa racionalidad empresarial del hacendado debe explicar, a saber: la de establecer cuáles eran los territorios más apetecidos por lo ganaderos en la fase inicial del despegue de esa actividad económica. El tratamiento de este tema demanda una reconstrucción de la geografía de las apropiaciones para observar las tierras sobre las que presionaba la expansión ganadera, y para ver como competían los diversos sectores que en ella participaban en procura de los recursos productivos. Así se podría conocer la dinámica de la sociedad agraria de la época y los conflictos que en determinadas circunstancias podían limitar o favorecer ese crecimiento. Esto significa que la comprensión de lo sucedido en el campo costeño durante la segunda mitad del siglo XIX y en la siguiente centuria obligatoriamente pasa por el estudio de los procedimientos y vías por medio de los cuales los diferentes sectores sociales de la región costeña pudieron apropiarse de los recursos públicos (tierras, agua, pastos y ganado cimarrón), y que este aspecto exige tener presente la existencia de unas relaciones entre algunos sectores sociales y el poder.

Comerciantes, hacendados, ganaderos, políticos, profesionales, indígenas, comunidades campesinas, agricultores residentes en los espacios urbanos, autoridades distritales y provinciales y del Estado y del departamento de Bolívar, se vieron gratificados o frustrados en sus aspiraciones de bienes materiales en concordancia con sus influencias y espacios de poder en las esferas de las autoridades y de las formas de poder que construyeron en sus espacios vitales y áreas de influencia. La concentración de una buena proporción de la riqueza pública de esta región en manos de un sector que a su ascendencia social unía su representatividad en las instituciones públicas y en otras esferas del poder político, institucional y social, se acentuó desde finales de los años 1860, cuando ganaderos de provincias empezaron a hacer presencia de manera creciente en la Asamblea Legislativa del Estado de Bolívar y en otros niveles de la administración pública, logrando imponer una política económica que les facilitaba el acceso a las tierras públicas y a las que se hallaban bajo regímenes corporativos de propiedad.

La racionalidad económica que impulsó la expansión de la ganadería originó enfrentamientos con comunidades indígenas y con vecindarios enteros debido a que su interés inicial no estuvo dirigido a apropiarse de cualquier clase de baldíos sino a las tierras más valorizadas tanto porque estaban civilizadas como por su cercanía a los centros urbanos, a las provisiones de pastos y aguas, a los principales caminos de tráfico y a los 
centros portuarios de acopio de reses con destino a la exportación ${ }^{36}$. En estos conflictos los ganaderos contaron con el beneplácito de las autoridades que veían que al fin se contaba con un producto para exportar y abastecer los mercados regionales, como también con la presencia de voceros de esta actividad económica en los organismos de poder regional desde donde impulsaron políticas públicas al servicio de esa actividad. Por tanto, creemos que el análisis de la expansión de la economía ganadera no se puede desligar de los factores de poder que favorecieron de los empresarios con las mayores cantidades y mejores tierras, y de los conflictos que suscitó el despojo de tierras comunales de uso colectivo y la apropiación de las tierras baldías que también eran usufructuadas por los campesinos $^{37}$.

No cabe la menor duda que, además de los políticos y hacendados, otros sectores también participaron en la apropiación de esas tierras, al igual que de los baldíos, aspecto que está a la espera de una investigación detallada que ilumine el complejo proceso. Pero la visibilidad en la información de los sectores más favorecidos obedece tanto a la prestancia social de que gozaban, como a que fueron mayores las proporciones de tierras que se apropiaron, lo que muestra claramente que la riqueza pública de esta región no se distribuyó de forma equitativa entre los diferentes sectores que integraban el tejido social agrario.

Por eso, es necesario un modelo de análisis que tenga en cuenta las relaciones existentes entre la expansión ganadera, la valorización de las tierras, la especialización de la producción ganadera, los grupos sociales y la instrumentalización del poder. La información menuda de los archivos locales que registra la cotidianidad económica, social y política, brinda una posición excepcional para observar ciertos procesos históricos y reconstruir el tejido de redes sociales y políticas intencionalmente urdidas y con propósitos definidos, que en el mayor de los casos no se pueden observar desde los archivos centrales ni a partir de los relatos de viajeros, de los despachos consulares y de los directorios $\operatorname{comerciales}^{38}$. Así que la información de los archivos locales alimentar nuevas interpretaciones que permiten que el debate no se cierre con las afirmaciones de Posada, y pese a la justeza de algunas de sus ideas, el modelo que critica no queda invalidado, dado que cuando se aplica y se le confronta con la información relativa a los sucesos ligados a la economía ganadera puede ser enriquecido para explicar de manera satisfactoria lo que sucedió en el mundo agrario costeño durante la segunda mitad del siglo XIX.

${ }^{36}$ Sergio Paolo Solano y Roicer Flórez, "Resguardos indígenas, ganaderías y conflictos sociales en el Bolívar Grande, 1850-1875”, en Historia Crítica № 34, Bogotá, Universidad de los Andes, 2007, pp. 92117; "La expropiación de las tierras del resguardo de Tubará y las normas jurídicas de la época", en Justicia $\mathrm{N}^{\circ}$ 12, Barranquilla, Universidad Simón Bolívar, 2077, pp. 81-89; "Indígenas, mestizaje, tierra y poder en el Caribe colombiano, siglo XIX", en Indiana N $^{\circ} 26$, Berlín Ibero-Amerikanisches Institut, 2009; Roicer Flórez, "Resguardos indígenas, ciudadanía y ganadería en el Estado Soberano de Bolívar, 18631875", en Trenzando $\mathrm{N}^{\circ}$ 1, Cartagena, Grupo de Trabajo Memoria, 2008, pp. 5-16; "Indígenas y ciudadanía en el Estado Soberano de Bolívar, 1863-1875", en Historia y Sociedad $\mathrm{N}^{\circ}$ 16, Medellín, Universidad Nacional, 2009.

${ }^{37}$ O. Fals, Resistencia en el San Jorge.

${ }^{38}$ Sergio Paolo Solano y Roicer Flórez, Hacendados y política en el Bolívar Grande 1850-1875 (Próximo a publicarse). 
En la documentación notarial de los años de 1860 en adelante se acentúan las transacciones comerciales de tierras en algunas áreas de la región en que se escenifica el crecimiento del hato ganadero, como también se manifiestan las preocupaciones de las autoridades de las provincias y distritos, de los resguardos indígenas y de los administradores de las tierras de mancomunidad, por compulsar copias de los títulos de propiedad de sus territorios ${ }^{39}$. En la prensa oficial del Estado y luego departamento de Bolívar reposan registros parciales de la denuncia, apropiación y legalización de baldíos, representaciones de comunidades indígenas y de campesinos que acudían a los mecanismos legales para exigir protección de sus derechos a la tierra, como también informes de las autoridades provinciales y distritales sobre conflictos entre agricultores y ganaderos por el usufructo de los ejidos y baldíos adyacentes a las poblaciones. Sobre este aspecto también aparecen las sentencias del Tribunal Superior de Justicia con atribuciones para intervenir disposiciones de los concejos distritales sobre la división de los ejidos en tierras de labor y de pasto, cuando lesionaba los intereses de algunas de las partes o lo que la costumbre había consagrado como norma. Toda esta información está coronada por una legislación regional que se encargó de expedir el camino para el desarrollo de la economía ganadera, y por los listados de contribución directa de los años de 1870 y el impuesto sobre la cría de ganado de 18661870, que muestran el desarrollo de diversos sectores sociales ligados a esa esfera productiva agropecuaria. Y sobre todo, en el Archivo General de la Nación de Colombia, reposan fondos documentales sobre las tierras de Bolívar y el Magdalena y sobre baldíos que ayudarían a tener una visión mucho más detallada de la participación de los distintos sectores sociales en los procesos de apropiación de las tierras.

Uno de los aspectos importante de esa información es precisamente que pone a la vista una geografía de las áreas sobre las que presionaba el crecimiento del hato ganadero, la demanda de tierra y los conflictos sociales, al tiempo que permite conocer quienes eran las personas y sectores sociales vinculadas a las diversas formas de propiedad del suelo, en especial a la hacienda, la prestancia social que se les reconocía y sus vínculos con el diversas formas de poderes, institucionales y no formales, que les servían para acceder a ese recurso productivo y para diseñar una legislación que favoreció a los ganaderos. Desde esta perspectiva la sociedad agraria costeña de ese periodo es más dinámica de lo que suele pensarse, pues se fue haciendo más compleja en la medida en que a la ganadería se vincularon diversos sectores sociales que se fueron moviendo en el espacio y chocaron con otros grupos ligados a formas más tradicionales de explotación del suelo.

Esta situación propiciada por la ganadería se hace evidente en los enfrentamientos con comunidades indígenas y con vecindarios enteros debido a que su interés inicial no estuvo dirigido a cualquier clase de baldíos sino a las tierras más valorizadas tanto porque estaban civilizadas como por su cercanía a los centros urbanos, a las provisiones de pastos y aguas,

${ }^{39}$ Sobre la importancia de la documentación notarial para investigar el problema de la propiedad territorial ver: Catherine LeGrand y Adriana Corso, "Los archivos notariales como fuente histórica: una visión desde la zona bananera del Magdalena", en Anuario Colombiano de Historia Social y de la Cultura $\mathrm{N}^{\circ} 31$, Bogotá, Universidad Nacional, 2004, pp. 159-208; Tomás Caballero, "Entre las ventas forzosas y la usura: el mercado del crédito en Barranquilla entre 1849-1886", en Historia Caribe $\mathrm{N}^{\circ}$ 13, Barranquilla, Universidad del Atlántico, 2008, pp. 227-250. 
a los principales caminos de tráfico y a los centros portuarios de acopio de reses con destino a la exportación. En estos conflictos el creciente sector de ganaderos contó, por un lado con la aceptación por parte de las autoridades que veían que al fin se daba con un producto para exportar y abastecer los mercados regionales, y por otra parte con la presencia de voceros de esta actividad económica en los organismos de poder regional desde donde impulsaron el diseño de políticas públicas al servicio de esa actividad. Por tanto, el análisis de la expansión de la economía ganadera no se puede desligar de los factores de poder que favorecieron de los empresarios con las mayores cantidades y mejores tierras, y de los conflictos que suscitó el despojo de tierras comunales de uso colectivo y la apropiación de las tierras baldías que también eran usufructuadas por los campesinos.

Por eso creemos que una cartografía de estos terrenos revelaría que buena parte de las grandes y medianas apropiaciones de tierras se concentraban en torno a los circuitos mercantiles más importantes, en especial de los terrenos comunales (ejidos) de los municipios y de los resguardos indígenas, y alrededor de las principales vías de comunicación. Las evidencias permiten aseverar que esas apropiaciones y acaparamientos fueron muy comunes en los alrededores de las ciudades portuarias costeñas y en las poblaciones de las diferentes provincias que formaban el Bolívar Grande, pues al convertirse sus principales poblaciones en escenarios de transacciones comerciales de ganado, los empresarios necesitaron cercar y controlar las tierras de las inmediaciones para llevar las reses a pastar para el engorde y venta en los mercados locales y del extranjero. Por tanto, puede afirmarse que en muchas ocasiones el problema no radicaba en la abundancia de recursos naturales, sino en acceder a los que se valorizaban gracias a que ya estaban civilizados e integrados a los circuitos mercantiles comarcanos y regionales que se fueron construyendo a lo largo del siglo XIX y comienzos del XX.

Entonces, la apropiación de la tierra por unos pocos avanzó más rápido en algunas zonas en que ese recurso estaba más valorizado por las razones que anotamos un poco atrás. De ahí que durante los años 1860, 1870 y 1880, los informes de los gobernadores provinciales del Estado de Bolívar señalen que el principal conflicto se vivía en torno a los terrenos del común (o ejidos o terrenos del distrito) contiguos a las poblaciones y por la apropiación de las tierras de los resguardos. Como resultado en parte de esta apropiación y cercamiento de las tierras públicas, la población de Barranquilla ocupada en las labores agropecuarias (siembra, ganadería, pesca y caza) pasó de representar el $26 \%$, al $6.2 \%$ y al $5.3 \%$, respectivamente de la PEA, según se lee en los censos de los años de 1875, 1912 y 1928. Y sin duda que esto también sucedió en el caso de Cartagena y de muchas otras poblaciones de la región.

Precisamente, nuestro punto de vista parte de los supuestos desechados E. Posada, pues consideramos que la sociedad agraria costeña del siglo XIX constituye un buen caso para ser investigado con base en un modelo sociológico e histórico propuesto para estudiar las peculiaridades del cambio social en las sociedades agrarias atrasadas, modelo que involucra cuatro elementos esenciales: la economía ganadera, la apropiación de recursos, 
el poder y la sociedad. Creemos que se debe distinguir entre ese modelo y las conclusiones a que hayan podido llegar algunos historiadores. Cuando se deja de lado el poder, elemento clave para comprender que empezó a suceder en el campo costeño con los recursos públicos desde mediados del siglo XIX, se presenta una visión muy ingenua de la sociedad. Es articulando el poder al análisis que se pueden comprender los mecanismos por medio de los cuales se accedía a las tierras públicas, tema que constituye uno de los nudos gordianos de la cuestión agraria. Más en una región como lo era la Costa del periodo que estudiamos, la que en muchísimas comarcas poseía todas las características sociales, económicas y políticas de los territorios de fronteras. Allí, la ausencia del poder estatal institucional es asumida por formas de poder más informales pero no por ello menos efectivas.

Esta condición llevó a que los conflictos entre agricultores y ganaderos, que a su vez involucraban a las autoridades distritales, provinciales y del Estado de Bolívar, se resolviera a favor de los ganaderos, y que la ganadería presionara y cercara a la agricultura de pan coger, que fue la que más sufrió, en especial la situada en las goteras de las poblaciones. Las expresiones institucionales de estas relaciones representan una buena muestra tanto de su permeabilidad a estos conflictos acerca, como de la instrumentalización del poder para ponerlo al servicio de unos intereses y de un modelo económico, la economía ganadera. Basta observar la conformación de las diputaciones provinciales a la Asamblea del Estado de Bolívar, para darse cuenta de cómo se fue planteando la relación política-ganadería, y como en el penúltimo periodo finisecular esa elite provincial ganadera se entronca con sectores de la elite cartagenera, recibiendo un segundo aliento esta última.

En su fase inicial o al menos hasta finales de los años 1880, la competencia por los recursos públicos se organizó en torno a tres espacios: los territorios de frontera de reciente colonización que por sus ubicaciones facilitaran la movilización del ganado hacia los mercados del interior del país o de la región; los terrenos más valorizados por su ubicación próxima a los centros de consumo, puertos de exportación, a los caminos por los que se movilizaba el ganado tanto cuando eran destinadas al sacrificio, como por el traslado a sabanas, playones y humedales. Ejidos, resguardos, tierras en mancomunidad, baldíos próximos a los poblados, fueron espacios disputados entre los diversos actores de la sociedad costeña, y en los sitios en los que hubiese disponibilidad de mano de obra. Todo esto indica que en sus comienzos no hubo tanto interés por los baldíos. Toda la atención y los esfuerzos se concentraban en las tierras valorizadas y en las ubicadas estratégicamente. Por las características del medio costeño, por tradición y por las fases de la producción ganadera (cría, levante y ceba), los sectores más favorecidos por esta actividad fraccionaron sus propiedades en concordancia con: disposición de pastos y aguas; disponibilidad de mano de obra; condiciones del terreno y del ambiente acorde con exigencias mínimas por cada fase de la producción, y cercanos a los caminos de movilización de las reses. Quizá esto explique que la gran hacienda costeña del tránsito del siglo XIX al XX no sobrepasara las 15.000 hectáreas. En muchos casos esas propiedades fragmentadas formaban una unidad empresarial que involucraba todas las fases de la ganadería. 
Las actitudes de la población campesinas frente a la propiedad territorial no están del todo claras. A partir de la segunda mitad de los años de 1870 los informes de los gobernadores provinciales del Bolívar Grande son reiterativos en una queja suscitada por el desinterés que mostraba el campesinado frente a la propiedad territorial, actitud en la que veían un serio obstáculo para el progreso de la "civilización" en esta región. La queja aparece en el momento en que la economía ganadera se está expandiendo y presionando sobre la propiedad territorial, lo que estaba acompañado de conflictos sociales por las disputas por las tierras de los resguardos de los indígenas y las de las comunidades de vecinos que las usufructuaban bajo la forma jurídica de los ejidos de las poblaciones. Todo llevaría a pensar que el campesinado pobre mostrara un interés por participar en las apropiaciones de baldíos y por hacerse a una heredad territorial, pero al parecer no fue así.

Esta actitud puede explicarse en razón de la tecnología agrícola primitiva que se empleaba en el laboreo del suelo, pues la quema de árboles y rastrojos días antes de la llegada del periodo de lluvias como única forma para abonar el terreno y la roza con instrumentos muy rudimentarios (machete y azadón) sin horadar lo suficiente la superficie y sin el empleo de irrigación artificial, obligaba a que la agricultura tuviera un carácter itinerante, pues luego de dos o tres año de estar sembrado la roza, la productividad del suelo se agotaba y el campesino tenía que volver a empezar en otro terreno que le arrebataba a la selva. Por tanto, los campesinos estaban interesados en aquellos terrenos públicos que, como los ejidos de las poblaciones y los baldíos próximos a aquellas, les garantizaban la suficiente provisión de terrenos para practicar sus métodos agrícolas tradicionales.

Esto no dejaba de ser una situación paradójica para las autoridades de la época que veían que en medio de la abundancia de ese recurso público el común de los labriegos no mostrara interés en apropiárselas debido a que estaban situadas a mucha distancia de los centros poblados. No interesaba cualquier tierra en cualquier lugar. En las fases iniciales de la economía ganadera y del mercado de tierras la competencia se concentraba alrededor de las tierras conocidas. Las disposiciones legales sobre el mundo rural contenidas en los códigos de policía del último cuarto del siglo XIX dan la impresión de un mundo agrario literalmente parroquial, es decir, el espacio vital del campesino casi se circunscribía a las goteras de las poblaciones. Al respecto, en 1880 el gobernador de la provincia de Chinú informaba sobre inmensos baldíos en los distritos de Ciénaga de Oro y Ayapel, y señalaba el poco interés en los mismos debido a su lejanía de los centros poblados. En esto, el peso de las tradiciones representaba un papel de primer orden. La migración hacia los territorios de frontera era el último recurso que querían agotar los campesinos costeños, descritos por el general Justo Durán en sus memorias de la Guerra de los Mil Días, cuando señaló que los soldados liberales costeños no querían combatir más allá de las goteras de sus poblaciones $^{40}$. El gobernador de la provincia de Mompox en 1880 creía que debía repartirse la tierra entre un gran número de propietarios, para que los que quedaran sin tierra por fin se verían obligados a “... pensar en cultivar las tierras que hasta hoy

${ }^{40}$ Justo L. Durán, La revolución del 99, Bogotá, talleres tip. El Día, 1920. 
permanecen incultas, solo porque están apartadas de la orilla del río Magdalena"41. En estos casos del poblamiento orillero a los ríos y caños, los asentamientos seguían un curso paralelo a las riberas, y las actitudes de los hombres no escapaban a la aspiración de estar próximos al curso de las aguas, tanto por los recursos que estas proveían como por la facilidad de las comunicaciones.

${ }^{41}$ BLAA, "Informe del gobernador de la provincia de Mompós" e "Informe del gobernador de la provincia de Chinú", en Diario de Bolivar, Cartagena, julio 15 y agosto 20 de 1880. (Cursivas nuestras). 